Psychother Psychosom 2014;83:190-191

DOI: $10.1159 / 000358525$

\section{Type D Personality in Never Depressed Patients at Their First Acute Coronary Syndrome}

\author{
Carlo Marchesi ${ }^{\mathrm{a}, \mathrm{b}}$, Paolo Ossola ${ }^{\mathrm{a}, \mathrm{b}}$, Francesca Scagnelli ${ }^{\mathrm{a}, \mathrm{b}}$, \\ Francesca Paglia ${ }^{\mathrm{a}, \mathrm{b}}$, Sonja Aprile ${ }^{\mathrm{a}, \mathrm{b}}$, Alberto Monici ${ }^{\mathrm{b}}$, \\ Matteo Tonna ${ }^{\mathrm{b}}$, Giulio Conte ${ }^{\mathrm{c}}$, Franco Masini ${ }^{\mathrm{c}}$, Chiara De Panfilis ${ }^{\mathrm{a}} \mathrm{b}$, \\ Diego Ardissino ${ }^{\mathrm{C}}$ \\ aPsychiatry Unit, Department of Neuroscience, University of \\ Parma, ${ }^{\mathrm{b}}$ Mental Health Department, AUSL, and ${ }^{\mathrm{C} D e p a r t m e n t}$ of \\ Cardiology, University Hospital, Parma, Italy
}

Distressed (type D) personality (TDP) [1] is characterized by high negative affectivity (NA) and social inhibition (SI), and can be assessed by means of a specific instrument (DS14). TDP, depression, anxiety and other negative affects (such as demoralization, hopelessness, pessimism and rumination) have been implicated as potential risk factors for coronary artery disease [2-4]. While some evidence suggests that the NA dimension of TDP overlaps at least partially with depression [5-7], other studies underline how 'TDP refers to a chronic, more covert form of distress that is distinct from depression' [8]. However, the stability of TDP is still far from being ascertained, with some studies indicating that TDP is a stable, mood-state-independent phenomenon, and others reporting that changes in TDP diagnosis occur in about $60 \%$ of patients after cardiac surgery [9], thereby suggesting that TDP includes a state-dependent component $[10,11]$. Therefore, the present study aims to clarify whether, among never depressed patients at their first acute coronary syndrome (ACS), there is an overlap between the constructs of TDP and depression, evaluating the stability of NA and SI 6 months after the ACS, and their relationship with depressive symptoms.

The Local Ethics Authority approved the study protocol. In the study, patients consecutively admitted to the Coronary Intensive Care Unit of the University Hospital of Parma between January 2009 and March 2012 were enrolled if: (a) they had their first ACS; (b) they had no history of major depression (MD); (c) they did not satisfy the Primary Care Evaluation of Mental Disorders (PRIME$\mathrm{MD}$ ) criteria for MD at baseline, and (d) they gave informed consent to participate in the study.

With a clinical interview, a psychiatrist excluded the presence of previous MD episodes according to the PRIME-MD criteria. Patients with minor depression (md) at baseline were included, with the aim to evaluate if md could influence the TPD assessment before the MD onset. Two hundred and fifty patients satisfied the inclusion criteria.

The presence of MD and md was evaluated with the PRIME$\mathrm{MD}$; the severity of depressive and anxious symptoms were as- sessed with the Hospital Anxiety and Depression Scale (HADS). The DS14 was used to diagnose TDP. Patients were evaluated at baseline (within the first 3 days after the ACS) and at 1, 2, 4 and 6 months of follow-up. In order to determine whether NA and SI vary along with the measures of depression and anxiety, an ANOVA for repeated measures was performed (DS14 and HADS subscales as dependent variables) over a 6-month follow-up after the ACS, comparing patients who developed MD or md during the study period with those who did not (independent variable).

During the follow-up period 30 patients developed depressive symptoms (MD: $\mathrm{n}=12$; $\mathrm{md}: \mathrm{n}=18$ ), whereas 220 subjects maintained a nondepressive condition throughout the study period. At baseline the NA and SI levels were higher in subjects who developed depression than in patients who did not (NA: $16.6 \pm 5.5$ vs. $8.7 \pm 5.8 ; \mathrm{t}=2.2 ;$ d.f. $=237 ; \mathrm{p}<0.001)($ SI: $13.8 \pm 3.1$ vs. $10.2 \pm 4.6$; $\mathrm{t}=2.1$; d.f. $=237 ; \mathrm{p}=0.03)$. However, at the baseline evaluation 19 patients without previous depressive episodes already satisfied the criteria for md. Interestingly, at baseline these subjects showed higher levels of NA and SI than subjects without $\mathrm{md}(\mathrm{n}=231$; NA: $16.6 \pm 5.5$ vs. $8.6 \pm 5.8 ; \mathrm{t}=5.7 ;$ d.f. $=248 ; \mathrm{p}<0.001)($ SI: $13.7 \pm 3.3$ vs. $10.3 \pm 4.7 ; \mathrm{t}=3.0$; d.f. $=248 ; \mathrm{p}<0.001)$.

Among patients who developed depression $(\mathrm{n}=30)$ HADS scores significantly changed during the 6-month follow-up: both anxiety and depression scores increased from baseline to the second month of follow-up and then decreased $(\mathrm{F}=8.8, \mathrm{p}<0.001$ and $\mathrm{F}=8.3, \mathrm{p}<0.001$, respectively). The same pattern of change was observed for the NA score $(\mathrm{F}=6.9 ; \mathrm{p}<0.001)$, whereas the SI score did not vary during follow-up $(F=1.0 ; p=0.41$, fig. 1$)$. In nondepressed patients, both HADS depression $(\mathrm{F}=27.4 ; \mathrm{p}<0.001)$ and anxiety $(F=15.6 ; \mathrm{p}<0.001)$ scores and NA score $(\mathrm{F}=4.2 ; \mathrm{p}=0.041)$ significantly decreased throughout the follow-period, whereas the SI did not change $(\mathrm{F}=1.8 ; \mathrm{p}=0.18)$.

This is, to our knowledge, the first study to evaluate patients with no history of MD at their first ACS. Thus, our assessment of TDP features could not be confounded by the duration of longlasting depressive or coronary illnesses, and in the current study sample, TPD is unlikely to represent a 'scar' following such diseases [5].

In our study, the overlap between depressive psychopathology and NA features is suggested by the course of these two dimensions over time. Indeed, in both depressed and nondepressed patients, NA levels were not stable during the 6-month follow-up, but they changed along with the variation of HADS scores. This finding suggests that the NA dimension is sensitive to mood-state, because its levels increase and decrease according to the fluctuation of severity of depressive and anxious symptoms. This result supports the view that the disposition to experience and report negative emotions (NA) can be sensitive to mood-state. These results confirm, and possibly explain, the long-recognized high association among measures of negative affect, particularly the NA component of TDP, and the self-reported measures of depressive symptoms [5-7]. Concerning TDP and its independency from emo-

\section{KARGER}

E-Mail karger@karger.com

www.karger.com/pps
C 2014 S. Karger AG, Basel

0033-3190/14/0833-0190\$39.50/0
Carlo Marchesi, MD

Psychiatry Unit, Department of Neuroscience, University of Parma

University Hospital, Braga Building

IT-43126 Parma (Italy)

E-Mail carlo.marchesi@unipr.it 


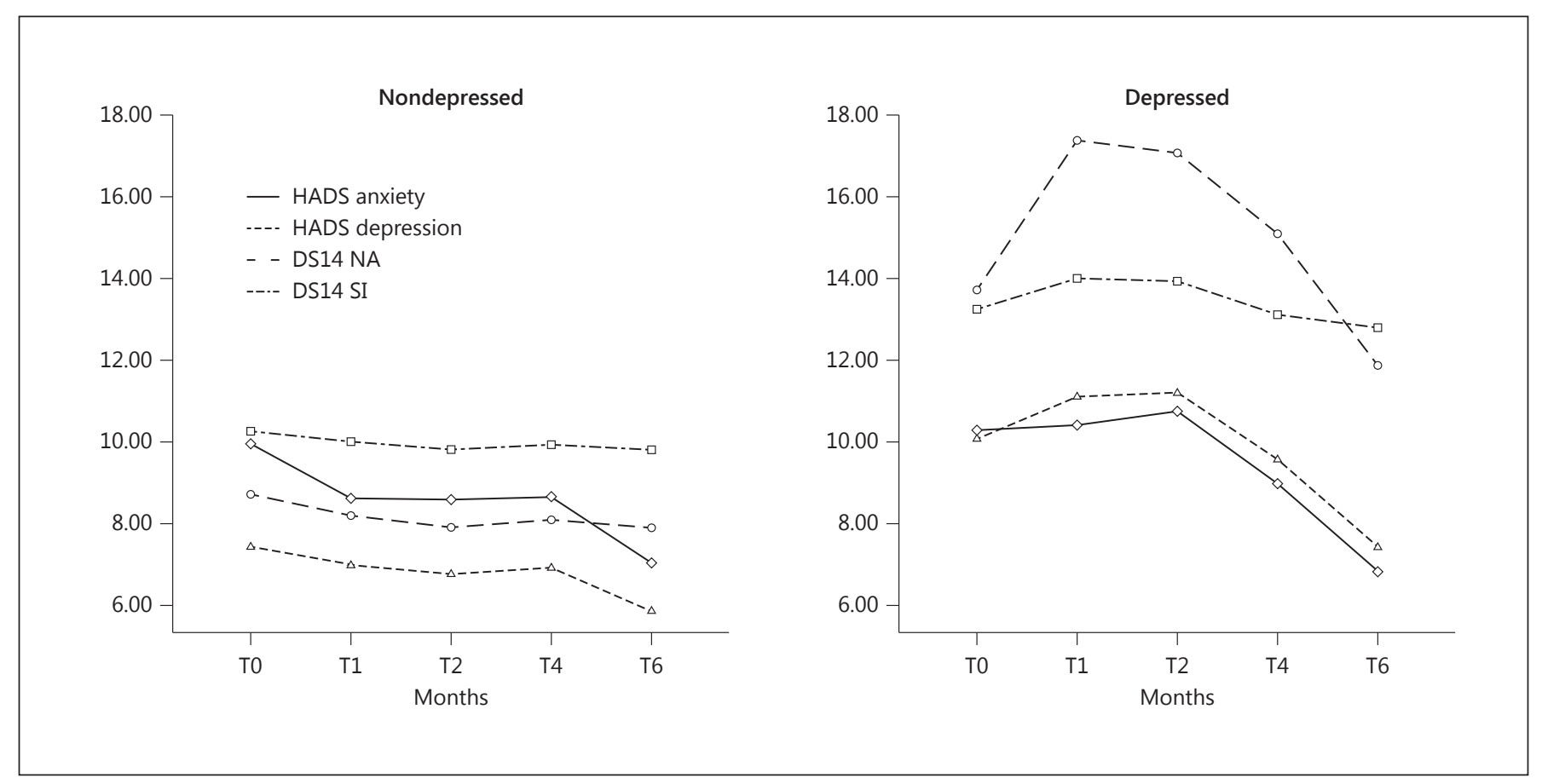

Fig. 1. Variation of the HADS and DS14 scores during the follow-up period in nondepressed and depressed patients.

tional distress [9], a recent study reported that TDP dimensions were stable over a long period of time [12]; however, that study did not control for co-occurring distress or affective psychopathology, while our findings suggest that even the presence of subthreshold depression (md) is associated with greater NA and SI. Therefore, the results of the present study suggest that the presence of depressive state is crucial when assessing TDP, since NA and anhedonic depression are partially overlapping and co-varying constructs.

\section{Disclosure Statement}

We declare that we have no conflict of interest.

\section{References}

$\checkmark 1$ Denollet J, Sys SU, Stroobant N, Rombouts H, Gillebert TC, Brutsaert DL: Personality as independent predictor of long-term mortality in patients with coronary heart disease. Lancet 1996;347:417-421.

$\checkmark 2$ Rutledge T, Linke SE, Krantz DS, Johnson BD, Bittner V, Eastwood JA, Eteiba W, Pepine CJ, Vaccarino V, Francis J, Vido DA, Merz CN: Comorbid depression and anxiety symptoms as predictors of cardiovascular events: results from the NHLBI-sponsored Women's Ischemia Syndrome Evaluation (WISE) study. Psychosom Med 2009;71:958-964.

- 3 Denollet J, Pedersen SS, Vrints CJ, Conraads VM: Predictive value of social inhibition and negative affectivity for cardiovascular events and mortality in patients with coronary artery disease: the type $\mathrm{D}$ personality construct. Psychosom Med 2013;75:873-881.

4 Rafanelli C, Sirri L, Grandi S, Fava GA: Is depression the wrong treatment target for improving outcome in coronary artery disease? Psychother Psychosom 2013;82:285-291.
5 Starrenburg AH, Kraaier K, Pedersen SS, van Hout M, Scholten M, van der Palen J: Association of psychiatric history and type D personality with symptoms of anxiety, depression, and health status prior to ICD implantation. Int J Behav Med 2013;20:425-433.

-6 Bergvik S, Sørlie T, Wynn R, Sexton H: Psychometric properties of the Type D scale (DS14) in Norwegian cardiac patients. Scand J Psychol 2010;51:334-340.

7 Kudielka BM, von Känel R, Gander ML, Fischer JE: The interrelationship of psychosocial risk factors for coronary artery disease in a working population: do we measure distinct or overlapping psychological concepts? Behav Med 2004;30:35-43.

8 Denollet J, Schiffer AA, Spek V: A general propensity to psychological distress affects cardiovascular outcomes: evidence from research on the type D (distressed) personality profile. Circ Cardiovasc Qual Outcomes 2010;3:546-557.

9 Dannemann S, Matschke K, Einsle F, Smucker MR, Zimmermann K, Joraschky P, Weidner K, Köllner V: Is type-D a stable construct? An examination of type-D personality in patients before and after cardiac surgery. J Psychosom Res 2010;69:101-109.

10 Spindler H, Kruse C, Zwisler AD, Pedersen SS: Increased anxiety and depression in Danish cardiac patients with a type D personality: crossvalidation of the Type D Scale (DS14). Int J Behav Med 2009;16:98-107.

11 Romppel M, Herrmann-Lingen C, Vesper JM, Grande G: Six year stability of Type-D personality in a German cohort of cardiac patients. J Psychosom Res 2012;72:136-141.

12 Kupper N, Boomsma DI, de Geus EJ, Denollet J, Willemsen G: Nine-year stability of type D personality: contributions of genes and environment. Psychosom Med 2011;73:75-82. 